\title{
An Internet-Based Health Communication Platform: Fostering Dialogue among University Faculty for Better Academics' Health
}

\author{
Sy-Chyi Wang ${ }^{1}$ and Jin-Yuan Chern ${ }^{2}$ \\ ${ }^{1}$ Dept. of E-learning Design and Management, National Chiayi University, Chiayi, Taiwan \\ ${ }^{2}$ Dept. of Health Care Administration, Chang Jung Christian University, Tainan, Taiwan \\ Correspondence should be addressed to: Jin-Yuan Chern; chern@mail.cjcu.edu.tw
}

Received 2 August 2012; Accepted 18 September 2012; Published 30 December 2012

Academic Editor: Seungbong Park

Copyright (C) 2012 Sy-Chyi Wang and Jin-Yuan Chern. Distributed under Creative Commons CC-BY 3.0

\begin{abstract}
This study aims to launch an e-health application to help motivate academics' active participation in health-promoting activities. It is an on-going project about understanding and enhancing academics' involvement in health-related activities.

An Internet-based platform coined as Preparing Academics' Health for Tomorrow's Education (PAHTE) was designed and implemented. Based on a pre-established health database, the PAHTE allows the users to conduct self-assessment of health status and obtain online feedback in visual demonstrations. A customized health profiling function is also provided to help the users keep tracking their health-promoting performance over time. It is expected that with this platform application academics may have a better opportunity to pay close attention to their health-related issues.
\end{abstract}

Keywords: Health communication, Internet-based, health promotion, academics.

\section{Introduction}

Teachers teach students to take good care of their health so as to prepare themselves for the future challenges of our society. Academics in higher education instruct prospective teachers how to maintain their health so that they may teach their future students to take care of their health.
Interestingly, who are supposed to remind academics of the importance of staying healthy?

In 1986, the World Health Organization (WHO) held the first International Conference on Health Promotion and presented the Ottawa Charter for action in response to growing expectations for a new

Cite this Article as: Sy-Chyi Wang and Jin-Yuan Chern (2012), "An Internet-Based Health Communication Platform: Fostering Dialogue among University Faculty for Better Academics' Health," Journal of e-Health Management, Vol. 2012 (2012), Article ID 221265, DOI: 10.5171/2012.221265 
public health movement (World Health Organization, 1986). The Ottawa Charter listed five action means to help the society to achieve the ultimate goal of health promotion (i.e. Health for All). Among the rest, the action means of "creating supportive environments" generated the Global School Health Initiative in 1995 to "improve the health of students, school personnel, families and other members of the community through schools" (WHO, 2007). Since then, the Health Promoting Schools Program has been widely applied around the world and many studies have been reported to discuss the effectiveness of relevant programs (Deschesnes et al., 2003; Ward et al., 2006).

Although applications of "creating supportive environments" have gone beyond schools into universities and many other settings in recent years (Chu et al., 2000; Dooris, 2001), so far few studies have used academic professionals as research subjects for a comprehensive understanding of their health behaviors and health status. Among the few studies focused on academic professionals, one survey(Wang \& Chern, 2007)showed that academics' overall health status displayed a worse profiling than the general population norms. In fact, over the past decade, more than a dozen of faculty members in Taiwan have been dying of cancer, acute myocardial infarction or other severe cardiovascular diseases (China Times, $2011 / 10 / 29$ ), which was believed related to overstress or burnout. While the analysis from the survey also revealed that the respondents' health status was significantly associated with the degree to which they participated in health-promoting activities, interestingly, more than half of the respondents reported that they undertook exercise just once or even less per week. When asked why they did not participate in physical activities regularly, most respondents gave such answers as "being tied up with academic matters," or "feeling stressful or burned-out after work." Nevertheless, the respondents also agreed that they would conduct health-promoting activities because of the advice, suggestion or encouragement from their friends or family, or campaigns of health information through mass media.

Interactive technologies can be used to facilitate theory-based interventions such as goal-setting, decisional balance sheets, relapse prevention activities, and planning and scheduling of activity (Papadakis, 2001). Especially, the information technology can be used to provide prompt feedback to patients (the degree of ability to meet activity targets, test results, etc.), and deliver motivational messages or cues as well as provide on-line education. In fact, many health communication campaigns have begun to integrate interactive web sites into overall communication strategies and found that interactive health communication generated far-reaching impact on health communication campaign strategies (Preece \& Ghozati, 2001).

Among the many information technologies adopted by health communication campaigns, the Internet has shown to be a potential and effective channel for the delivery of physical activity interventions (Ferney \& Marshall, 2006). For example, Winett and colleagues (2005) demonstrated that the use of longer-term Internet programs was a promising approach to weight- gain prevention. McKay et al. (2001) evaluated the impact of an Internet-based intervention in a diabetes population and found moderate improvements in physical activity levels; those who used the Internet sites more regularly gained significantly greater benefits than their counterparts. Napolinato and colleagues (2003) ever concluded that website-delivered health behavior interventions would become increasingly useful in public health promotion as the Internet access increased, and as bandwidth and other technical attributes of this medium improved.

Indeed, the web-based platform provides an ideal environment for interactivity and peerto-peer interaction. While the interactive modes of applications were shown to be most effective with youth (Lynagh et al., 
1997), it was also argued that the applications could be tailored to a specific population or targeted to a broader population-level context, depending on the aim of the health promotion initiative (Skinner et al., 2006). In fact, applications of web-based programs have been widespread across different age groups of population such as teenagers, adolescents, adults and the elderly, and among different targeted populations (Rains, 2008; Spoel, 2008; Suggs, 2006).

In summary, over the years, the rapid growth of information technologies (especially the Internet) has created innovative opportunities for web-based health education and behavior change applications (Hoyo-Barbolla et al., 2006). The researchers' attention stems from whether it is about time for health promotion policymakers, researchers and practitioners to reflect on the concept of "creating supportive environments" and to consider developing supportive health-promoting programs for academics as done for students through the implementation of information technologies (e.g. the Internet).

\section{Purposes of this Study}

The current study aims to develop a webbased health communication platform dedicated to academics or those who were interested in academics' health-related issues. Briefly, the purposes of this study are threefold.

1. To establish a web-based database system to profile academics' health information as a whole. Any newcomers or members logging onto this platform can locate his/her status quo along the spectrum of health-related scales based on the input data (responses to relevant online questionnaires). Through the online collection of academics' health information, the existing academics' health database can be updated from time to time.
2. To provide a customized health profiling for each member who contributes to the database. This customized functioning will provide each member not only their current health status compared to the specific group of their kind, but also his/her trend over the course in a more efficient and effective way.

3. To create a "cyber center" providing health information searching and referencing functioning with focus on health-promoting-activity-related news, facts, information, knowledge and resources. Through these channels, it is expected that academics would have a higher level of motivation to exercise more frequently.

\section{Methods}

This study is an on-going project about providing academics with health-related information to help promote their own health or at least, release their health concerns through encouragement of active participation in physical activities. In light of the goals and target population of this study, the e-Health platform was coined as Preparing Academics' Health for Tomorrow's Education (abbreviated as PAHTE).

\section{Data Sources}

The concept of this project study originated from its two preceding research projects which were implemented to gain a better understanding of academics' health belief, health behavior and health status. Based on two waves of health survey conducted one year apart, health-related information along with certain demographics (age, gender, academic rank, domain of profession, etc.) were collected from academics serving among 159 universities/colleges nationwide in Taiwan. In total, more than 3,000 participants (about $6.6 \%$ of the targeted population) were involved. 


\section{Process of the Development}

The procedure for the development of this PAHTE platform is flowcharted in Figure 1. This study is still going on at the stage of prototype testing. It is expected that with the completion of this PAHTE platform, academics might have a better opportunity to reflect on their health-related issues.

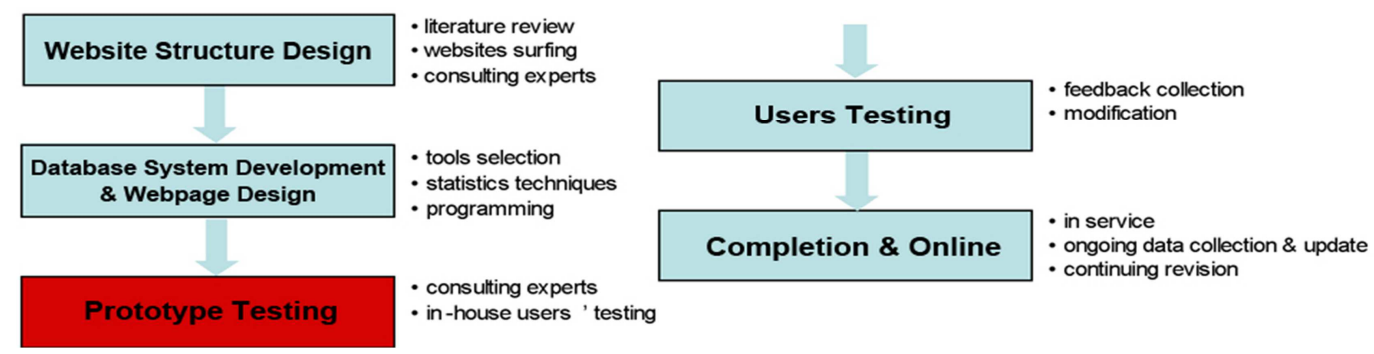

Figure 1. A Flowchart for the Development of the PAHTE Platform

\section{Overview of the Website Map}

The design of the PAHTE platform puts emphasis on the usefulness and easy-touse structure as shown in Figure 2.

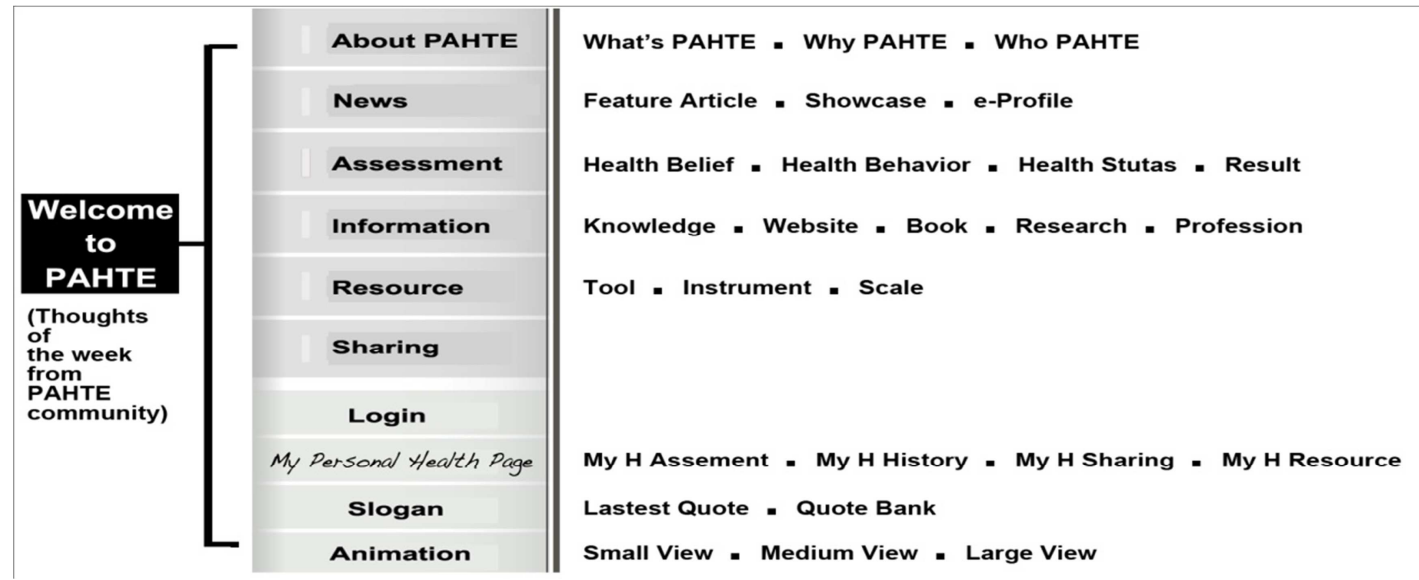

Figure 2. Structure of the Health Communication Platform

- About PTHTE: an introduction of the project; describing project background, goals, sponsors, etc.

- News: providing up-to-date healthpromoting-activity-related news, articles, showcases in the country for visitors' reference.

- Assessment: showing the locale of the visitor's (logged in) health along the spectrum of corresponding scale based on academics' overall performance generated from the updated database.

- Information: including hyperlinks to relevant websites, research, professional knowledge and useful/interesting information available from other resources.

- Resources: offering some practical and useful tools, instruments, or scales for academics' handy use.

- Sharing: allowing the user to share (post) their reflection, idea, comments, etc. 
- Login: acting as a checking post to make sure logging in visitors are from the academia by verifying their email addresses.

- My Personal Health Page: providing customized health profiling web pages for users.

- Slogan: reminding, encouraging, or alerting visitors to beware the benefits of taking physical activities.

- Animation: a collection of exercise demonstrations.

\section{Preliminary Results}

\section{Port of Entry for the PAHTE Platform}

Figure 3 (a screenshot from the created site) is the visual presentation of the PAHTE platform. As in some similar health websites, the PAHTE platform also provides information-based content services such as "news", "information" and "resource links." Through these channels, the users may search for or obtain certain helpful information of their own interest. Even, at the user's request, this platform may serve as a "health reminder" by sending out information messages or exercise alerts to urge the user to initiate necessary actions.

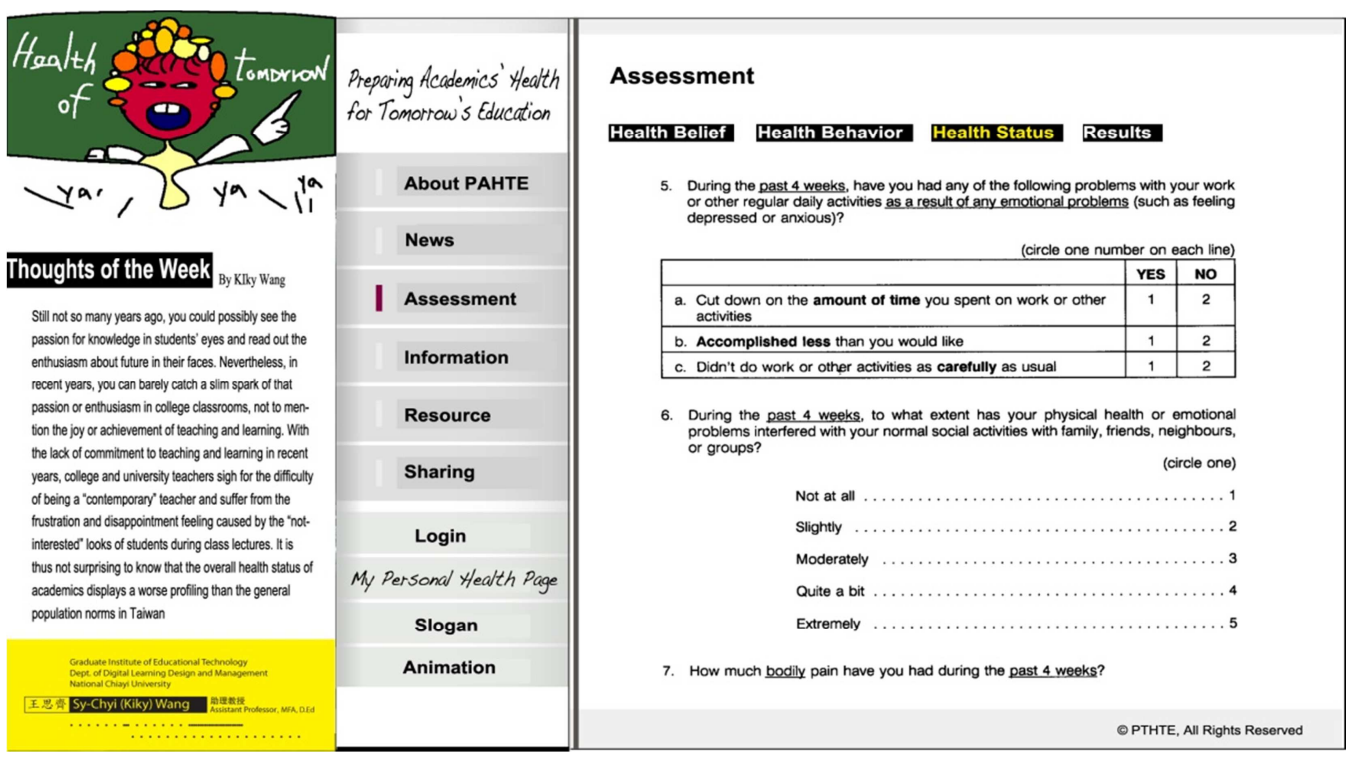

Figure 3. A Visual Presentation of the PAHTE Platform

Description of the Health Communication Platform Functions

The functions of each pull-down menu (refer to Figure 3) are designed and described in details as follows.

In the "About PAHTE," the origin of the project, the goals of the project, and the targeted users of this platform are described to help visitors better understand what, by whom and for whom the platform is intended. From the "News" and "Information," the users can search for and obtain updated information and news related to health promotion activities provided by external authorities or organizations.

When the member logs in as a first-time user or after a certain period of time, they may want to take or re-take the online questionnaire and check how their health status is compared to either the peers or the past with a graphic demonstration (see, for 
example, Figure 4). Further, the input data used to generate the visual demonstration of their health performance will then be collected and built into the back-end database automatically to keep the database up-to-date.

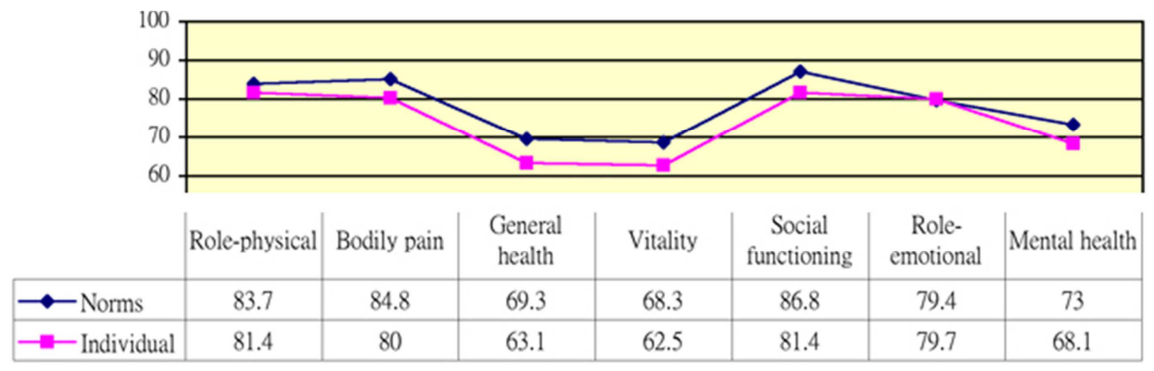

Figure 4. A Visual Demonstration of the User's Health Performance Compared to the Peer.

Each user's health history and shared thoughts and information will be built into the "My Personal Health Page" database so that it can be retrieved later by the user when necessary. Besides, a collection of 2D and/or 3D animations related to healthy behaviors for computer use will be established for users' reference. In brief, the PAHTE platform not only provides current health-related assessment, but also allows the user to create their customized online health profiling. With the health profiling service, the user may gain a quick glance at their health trend over a certain period of time and decide whether (and how) to adjust the lifestyle correspondingly.

\section{Discussion and Conclusions}

Some pioneer users have demonstrated their positive support of the health communication platform. For example, one trial member stated that "Well, I didn't know that my health status was that bad until I compared my health profiling to my peers."Another said, "It surely is a good idea to keep track of your health history online for yourself, especially when more and more people have easy access to the Internet nowadays. With this function, the user not only has a chance to compare his/her health profiling to others, but also has the capability of assessing his/her 'current' status with 'previous' status."

Nevertheless, two practical issues were also raised that needed to be addressed in the initial stage. First, to the researchers' best knowledge, so far this is the first Internetbased health communication platform with exclusive focus on academics, which would supposedly make it attractive to the targeted population on the one hand. However, on the other hand, what causes the researchers' concern is whether the academics would really be willing to spare their valuable time surfing the platform to make full use of its potential benefits if they have been "tied up with academic matters" or "feeling burnedout after work."Hopefully, as mentioned in one study (Wang \& Chern, 2007) that people would conduct health promoting activities if their friends or family suggested that they do so, or if they happened to run into health information campaigns through mass media. In light of the preceding, the next challenge would be how to make the visit of the health communication platform a routine in academics' already tied-up daily schedules. Second, the visual demonstration of the user's health performance compared to the peer seemed appealing and might have the potential to attract academics' attention to join the community. However, the users would also like to know how to improve the health dimensions with relatively lower scores in comparison with the peer or the past. Therefore, a consultation with domain experts is expected for modification in future studies.

In summary, the fundamental database has been established and the structure and 
framework of web pages has been developed. The prototype testing is under way. After completion, a more thorough statistical analysis of hypothesis testing will be conducted to examine whether the users (academics) of this platform demonstrate better health status and perform more healthy behaviors as opposed to the point of time before the use of the health communication platform.

\section{Acknowledgement}

Part of the materials was generated from the projects fundedby the National Science Council, Taiwan (NSC 93-2516-S-309-001 / NSC 94-2516-S-309-001).

\section{References}

China Times (2011/10/29). "The Overstressed Academic Profession," [in Chinese] [Online] [Retrieved July 2, 2012]. Available: http://news.chinatimes.com.

Chu, C., Breucker, G., Harris, N., Stitzel, A., Gan, X., Gu, X. \& Dwyer, S. (2000). "Healthpromoting Workplaces-International Settings Development," Health Promotion International, 15 (2), 155-167.

Deschesnes, M., Martin, C. \& Hill, A. J. (2003). "Comprehensive Approaches to School Health Promotion: How to Achieve Broader Implementation?," Health Promotion International, 18 (4), 387-396.

Dooris, M. (2001). "The 'Health Promoting University': A Critical Exploration of Theory and Practice," Health Education, 101 (2), 5160.

Ferney, S. L. \& Marshall, A. L. (2006). "Website Physical Activity Interventions: Preferences of Potential Users," Health Education Research, 21 (4), 560-566.

Hoyo-Barbolla, E., Arredondo, M. T., OrtegaPortillo, M., Fernandez, N. \& Villalba-Mora, E. (2006). "A New Approach to Model the Adoption of e-Health," Proceedings of the 13th
IEEE Mediterranean Electrotechnical Conference (MELECON 2006). Malaga, 16-19 May 2006, pp. 1209-1212.

Lynagh, M., Schofield, M. J. \& Sanson-Fisher, R. (1997). "School Health Promotion Programs over the Past Decade: A Review of the Smoking, Alcohol and Solar Protection Literature," Health Promotion International, 12 (1), 43-60.

McKay, H. G., King, D., Eakin, E. G., Seeley, J. R. \& Glasgow, R. E. (2001). "The Diabetes Network Internet-based Physical Activity Intervention: A Randomized Pilot Study," Diabetes Care, 24 (8), 1328-1334.

Napolitano, M. A, Fotheringham, M., Tate, D., Sciamanna, C., Leslie, E., Owen, N., Bauman, A. \& Marcus, B. (2003). "Evaluation of an Internet-based Physical Activity Intervention: A Preliminary Investigation," Annals of Behavioral Medicine,25 (2), 92-99.

Papadakis, S. (2001 September). 'Interactive Computer Technology and Cardiac Rehabilitation,' CACRC Newsletter.

Preece, J. J. \& Ghozati, K. (2001). "Experiencing Empathy Online," In Rice, RE.and Katz, JE. (Eds.) The Internet and Health Communication: Experiences and Expectations, 147-166. London: Sage.

Rains, S. A. (2008). "Health at High Speed: Broadband Internet Access, Health Communication, and the Digital Divide," Communication Research, 35(3),283-297.

Skinner, H. A., Maley, O. \& Norman, C. D. (2006). "Developing Internet-based eHealth Promotion Programs: The Spiral Technology Action Research (STAR) Model," Health Promotion Practice, 7 (4), 406-417.

Spoel, P. (2008). "Communicating Values, Valuing Community through Health-Care Websites: Midwifery's Online Ethos and Public Communication in Ontario," Technical Communication Quarterly, 17(3), 264-288. 
Suggs, L. S. (2006). "A 10-Year Retrospective of Research in New Technologies for Health Communication," Journal of Health Communication: International Perspectives, 11(1), 61-74.

Wang, S. Y. \& Chern, J. Y. (2007). 'Discord of Health Belief, Health Behavior, and Health Status among Taiwanese Academics,' Presented at the 19thIUHPE World Conference on Health Promotion and Health Education, June 10-15, 2007, Vancouver, BC, Canada.

Ward, D., Saunders, R., Felton, G., Williams, E., Epping, J. \& Pate, R. (2006). "Implementation of a School Environment Intervention to Increase Physical Activity in High School Girls," Health Education Research, 21 (6), 896910.

Winett, R. A., Tate, D. F., Anderson, D. S., Wojcik, J. R. \& Winett, S. G. (2005). "Longterm Weight Gain Prevention: A Theoretically Based Internet Approach," Preventive Medicine, 41 (2), 629-641.

World Health Organization (1986). "Ottawa Charter for Health Promotion," [Online], WHO, Geneva.[Retrieved July 2, 2012].Available:

http://www.who.int/healthpromotion/confe rences/previous/ottawa/en/index.html

World Health Organization (2007). Global School Health Initiative. [Online], WHO, Geneva.[Retrieved July 2, 2012]. Available: http://www.who.int/school_youth_health/gs hi/en/ 